\title{
Corollary discharges and fatigue-related symptoms: the role of attentional focus
}

\author{
Marcelo Bigliassi * \\ Department of Life Sciences, Brunel University London, Middlesex, UK
}

Keywords: fatigue, attention, exercise, brain, sensory aids

\section{Theoretical Backdrop}

Why do we stop? This question has intrigued researchers and exercise professionals worldwide (Noakes, 2000; Marcora, 2010; Amann et al., 2013). The answer is apparently linked to peripheral and cortical changes (Gandevia, 2001). Interestingly, most researchers are uncertain about the real mechanisms that underlie fatigue and task disengagement during exercise (Shephard, 2009). Due to the fact that fatigue-related symptoms are connected to psychophysiological changes and exercise performance, this question is paramount to understand the exercising human body (Marcora, 2008). Compelling evidence suggests that both peripheral changes and cortical activity create the sense of effort (Noakes, 2011). In such instance, the magnitude imposed by both cortical and peripheral changes will be determined in accord with the exercise mode and intensity. The present piece of work aims to provide an update on the psychobiological model (Pageaux, 2014) based on the evidence that attentional focus manipulates exerciser's consciousness with consequent effects on exertional responses and exercise performance (Lohse et al., 2010; Lohse and Sherwood, 2011). "The psychobiological model is an effort-based decision making model based on motivational intensity theory, and postulates that the conscious regulation of pace is determined primarily by five different cognitive/motivational factors: Perception of effort; potential motivation; knowledge of the distance/time to cover; knowledge of the distance/time remaining; previous experience/memory of perception of effort during exercise of varying intensity and duration" (Pageaux, 2014). An integrative model has been developed to underpin psychological responses that occur in response to the increasing exercise intensity.

\section{When the Brain Decides to Stop}

This article was submitted to Movement Science and Sport

Psychology, a section of the journal

Frontiers in Psychology

Received: 05 June 2015

Accepted: 02 July 2015

Published: 14 July 2015

Citation:

Bigliassi M (2015) Corollary discharges and fatigue-related

symptoms: the role of attentional

focus. Front. Psychol. 6:1002.

doi: 10.3389/fpsyg.2015.01002

There must be a purpose for animals to act the way they do (Darwin, 1859). The brain commands the whole body through a sequence of neural outputs. When humans do not want to exercise, they simply stop, meaning that motivation plays a central role in exercise engagement (Marcora, 2008). However, there are physical and mechanical limits imposed by the human structure. Motivational stimuli such as music and video have been extensively used in the field of sport and exercise as a means by which to increase situational motivation with consequent impact upon exercise performance (Karageorghis et al., 2013; Hutchinson et al., 2015). When sensory strategies are used during exercise tasks, the exerciser initially reallocates his/her attentional focus to the stimulus. This attentional switching caused by the relevance of the stimulus can modulate psychophysiological variables over time (Razon et al., 2009). In such application, the sensory stimulus competes for attention (Rejeski, 1985); therefore, the human brain selects the most relevant signals 
and gives these the most attention (Treisman, 1964). The increasing exercise intensity forces the brain to focus on the signals of exertion, because those are considered as more relevant to finish the trial successfully (Hutchinson and Tenenbaum, 2007; Wittekind et al., 2011).

Afferent feedback from visceral organs are theorized to influence attentional focus by increasing exertional responses (Hutchinson and Karageorghis, 2013). In such instance, sensory strategies such as auditory and visual stimuli are capable of ameliorating fatigue-related symptoms by competing for attention (Hutchinson et al., 2015). However, compelling evidence indicates that exertion might be not influenced by afferent feedback; patients with transplanted heart reported similar rate of perceived exertion (RPE) during exercise-related situations (Braith et al., 1992). The same results have been previously reported with epidural anesthesia, which blocks afferent signals from the working muscles (Fernandes et al., 1990), meaning that cortical activity is certainly associated with exertional responses and may be only partially connected to peripheral changes (Pollak et al., 2014). In this case, the central motor command apparently emits parallel messages (corollary discharges) to the brain regions associated with exertion as a means by which to create the sense of effort (De Morree et al., 2014).

In order to demonstrate that corollary discharges are responsible for influencing RPE, researchers have used hypnosis to recreate the exercise sensations (Williamson et al., 2002). In such application, exertional responses are theorized to be exclusively representative of cortical activity because participants were comfortably still. Williamson et al. (2001) used hypnosis to recreate the sensations of cycling downhill and uphill. When participants pictured themselves in such situations, they reported greater exertion during the uphill condition. This study demonstrated that the brain regions associated with exertion are at least partially influenced by cortical activity, because participants did not achieve maximal levels of exertion.

During exercise conditions, psychophysical phenomena such as motivation, perception of effort, and sensory information act upon voluntary control and neural activation of the working muscles (McCormick et al., 2015). Corollary discharges are hypothesized to be sent from the central motor command to many brain regions; those signals regulate perceived exertion, which negatively influences exercise engagement (De Morree et al., 2012). However, corollary signals can also act upon motivation and self-belief. In this case, corollary signals assume inhibitory characteristics, which decrease neural activation by making perceived exertion the only variable capable of influencing voluntary control.

It is also important to point out that conscious processes can generate positive signals to compete with corollary signals. In other words, people can resist this negative influence through conscious motivation (e.g., self-talk; see Blanchfield et al., 2014). It is noteworthy that awareness and sensory information can also have negative influences on voluntary control; for example, if the exerciser engages in negative selftalk or listens to unpleasant music while running. Those negative influences are theorized to decrease motivational state and increase perceived exertion. In addition, brain responses to high levels of anxiety are also responsible for increasing perception of effort and decreasing voluntary control with negative influence on performance (Parry et al., 2011). Therefore, it is postulated that a greater amount of corollary discharge might be sent to sensory regions of the brain, reducing efferent signals, and muscle activity.

\section{The Role of Attentional Focus}

The current piece of work postulates that attentional focus is the trigger responsible for modulating psychological responses to exercise. In such instance, the exerciser initially reallocates his/her attentional focus to the stimulus considered more relevant (Broadbent, 1958; Razon et al., 2012). Exercisers are able to focus on task-unrelated cues at low-intensity exercise, because the exercise task is considerably easy (for details, see Hutchinson and Tenenbaum, 2007). As soon as the exercise intensity increases, the human brain reallocates the attentional focus to internal sensory cues such as corollary discharges. This process occurs several times throughout the exercise cycle depending on the stimulus relevance (Tenenbaum and Connolly, 2008). Hence, attentional focus controls the exerciser's awareness to associative or dissociative thoughts, with subsequent impact upon exertional responses and exercise performance (see Ille et al., 2013).

Attentional focus is manipulated according to the signal relevance (Treisman, 1964). In such instance, sensory stimulation can reallocate attention to task-unrelated cues such as auditory and visual stimuli (Loizou and Karageorghis, 2015). If the sensory stimulus receives greater attention, the processing of corollary signals is attenuated, because the brain has limited capacity to process internal and external sensory cues (Rejeski, 1985). The distractive response induced by the sensory stimulus is capable of enhancing situational motivation and ameliorating the effects of fatigue-related symptoms even at high-intensity exercises (Boutcher and Trenske, 1990; Jones et al., 2014). Regardless of the source of internal processes (corollary discharges or afferent feedback), environmental influences compete for attention throughout the exercise cycle. Therefore, selective attention between external and internal sensory cues is in charge of initiating cascade reactions to psychophysical responses (Figure 1).

\section{No More Headless Bodies Walking Alone}

The information provided in this piece of work indicates that this field of research is hitherto under-researched. Researchers are encouraged to investigate the cortical and psychophysiological mechanisms that underlie task disengagement during wholebody modes of exercise. The answer might be associated with a constant flow of information between the brain and periphery. The psychological mechanisms that underlie task disengagement during exercise apparently interact with each other in order to define the moment at which humans stop exercising. Attentional focus appears to be the trigger responsible 


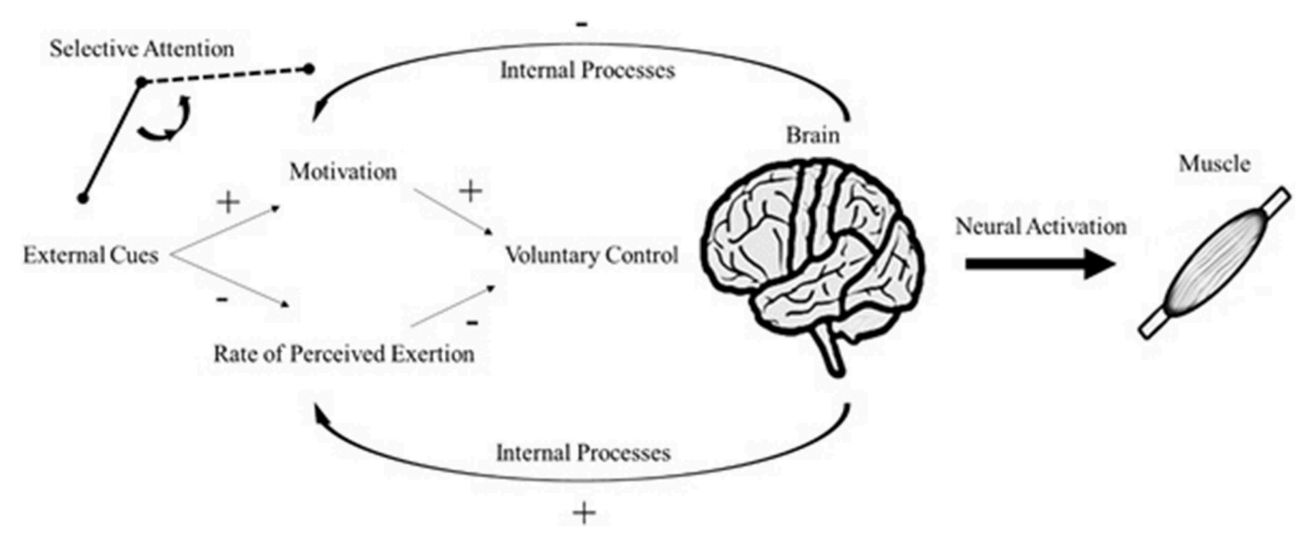

FIGURE 1 | An update on the psychobiological model of endurance performance. Plus signs represent a positive effect on the subsequent response; conversely, minus signs represent a negative effect on the subsequent response (e.g., internal processes decrease motivation and increase RPE).

for initiating cascade reactions that underpin the sense of effort and the neural activation to the active muscles. The exercise mode and intensity influence exertional responses over time (Razon et al., 2012). Sensory stimulation/deprivation and attentional strategies (associative or dissociative behavior) can facilitate or jeopardize exercise performance.

\section{References}

Amann, M., Venturelli, M., Ives, S. J., McDaniel, J., Layec, G., Rossman, M. J., et al. (2013). Peripheral fatigue limits endurance exercise via a sensory feedback-mediated reduction in spinal motoneuronal output. J. Appl. Physiol. 115, 355-364. doi: 10.1152/japplphysiol.0004 9.2013

Blanchfield, A. W., Hardy, J., De Morree, H. M., Staiano, W., and Marcora, S. M. (2014). Talking yourself out of exhaustion: the effects of self-talk on endurance performance. Med. Sci. Sport. Exerc. 46, 998-1007. doi: 10.1249/MSS.0000000000000184

Boutcher, S., and Trenske, M. (1990). The effects of sensory deprivation and music on perceived exertion and affect during exercise. J. Sport Exerc. Psychol. 12, 167-176.

Braith, R. W., Wood, C. E., Limacher, M. C., Pollock, M. L., Lowenthal, D. T., Phillips, M. I., et al. (1992). Abnormal neuroendocrine responses during exercise in heart transplant recipients. Circulation 86, 1453-1463. doi: 10.1161/01.CIR.86.5.1453

Broadbent, D. E. (1958). Perception and Communication. Elmsford, NY: Pergamon Press, Inc.

Darwin, C. (1859). On the Origin of Species. London: John Murray.

De Morree, H. M., Klein, C., and Marcora, S. M. (2012). Perception of effort reflects central motor command during movement execution. Psychophysiology $\quad 49, \quad 1242-1253 . \quad$ doi: $\quad 10.1111 / j .1469-8986.2012$. 01399.x

De Morree, H. M., Klein, C., and Marcora, S. M. (2014). Cortical substrates of the effects of caffeine and time-on-task on perception of effort. J. Appl. Physiol. 117, 1514-1523. doi: 10.1152/japplphysiol.00898.2013

Fernandes, A., Galbo, H., Kjaer, M., Mitchell, J., Secher, N., and Thomas, S. (1990). Cardiovascular and ventilatory responses to dynamic exercise during epidural anesthesia in man. J. Physiol. 420, 281-293. doi: 10.1113/jphysiol.1990.sp017912

Gandevia, S. C. (2001). Spinal and supraspinal factors in human muscle fatigue. Physiol. Rev. 81, 1725-1789.

\section{Acknowledgments}

MB is immensely grateful to Ricardo Santos Oliveira for his comments on an earlier version of this paper. This research was supported in part by grants from the Coordenação de Aperfeiçoamento de Pessoal de Nível Superior (CAPES).

Hutchinson, J. C., and Karageorghis, C. I. (2013). Moderating influence of dominant attentional style and exercise intensity on responses to asynchronous music. J. Sport Exerc. Psychol. 35, 625-643.

Hutchinson, J. C., Karageorghis, C. I., and Jones, L. (2015). See hear: psychological effects of music and music-video during treadmill running. Ann. Behav. Med. 49, 199-211. doi: 10.1007/s12160-014-9647-2

Hutchinson, J. C., and Tenenbaum, G. (2007). Attention focus during physical effort: the mediating role of task intensity. Psychol. Sport Exerc. 8, 233-245. doi: 10.1016/j.psychsport.2006.03.006

Ille, A., Selin, I., Do, M., and Thon, B. (2013). Attentional focus effects on sprint start performance as a function of skill level. J. Sports Sci. 31, 1705-1712. doi: 10.1080/02640414.2013.797097

Jones, L., Karageorghis, C. I., and Ekkekakis, P. (2014). Can high-intensity exercise be more pleasant? Attentional dissociation using music and video. J. Sport Exerc. Psychol. 36, 528-541. doi: 10.1123/jsep.2014-0251

Karageorghis, C. I., Hutchinson, J. C., Jones, L., Farmer, H. L., Ayhan, M. S., Wilson, R. C., et al. (2013). Psychological, psychophysical, and ergogenic effects of music in swimming. Psychol. Sport Exerc. 14, 560-568. doi: 10.1016/j.psychsport.2013.01.009

Lohse, K. R., and Sherwood, D. E. (2011). Defining the focus of attention: effects of attention on perceived exertion and fatigue. Front. Psychol. 2:332. doi: $10.3389 /$ fpsyg. 2011.00332

Lohse, K. R., Sherwood, D. E., and Healy, A. F. (2010). How changing the focus of attention affects performance, kinematics, and electromyography in dart throwing. Hum. Mov. Sci. 29, 542-555. doi: 10.1016/j.humov.2010. 05.001

Loizou, G., and Karageorghis, C. I. (2015). Effects of psychological priming, video, and music on anaerobic exercise performance. Scand. J. Med. Sci. Sports 1, 1-12. doi: $10.1111 / \mathrm{sms} .12391$

Marcora, S. M. (2008). Do we really need a central governor to explain brain regulation of exercise performance? Eur. J. Appl. Physiol. 104, 929-931; author reply: 933-935. doi: 10.1007/s00421-008-0818-3

Marcora, S. M. (2010). Rebuttal from marcora. J. Appl. Physiol. 108, 457. doi: 10.1152/japplphysiol.00976.2009c 
McCormick, A., Meijen, C., and Marcora, S. (2015). Psychological determinants of whole-body endurance performance. Sports Med. 45, 997-1015. doi: 10.1007/s40279-015-0319-6

Noakes, T. (2000). Physiological models to understand exercise fatigue and the adaptations that predict or enhance athletic performance. Scand. J. Med. Sci. Sports 10, 123-145. doi: 10.1034/j.1600-0838.2000.010003123.x

Noakes, T. (2011). Time to move beyond a brainless exercise physiology: the evidence for complex regulation of human exercise performance. Appl. Physiol. Nutr. Metab. 36, 23-35. doi: 10.1139/H10-082

Pageaux, B. (2014). The psychobiological model of endurance performance: an effort-based decision-making theory to explain self-paced endurance performance. Sport. Med. 44, 1319-1320. doi: 10.1007/s40279-014-0198-2

Parry, D., Chinnasamy, C., Papadopoulou, E., Noakes, T., and Micklewright, D. (2011). Cognition and performance: anxiety, mood and perceived exertion among Ironman triathletes. Br. J. Sports Med. 45, 1088-1094. doi: 10.1136/bjsm.2010.072637

Pollak, K. A., Swenson, J. D., Vanhaitsma, T. A., Hughen, R. W., Jo, D., Light, K. C., et al. (2014). Exogenously applied muscle metabolites synergistically evoke sensations of muscle fatigue and pain in human subjects. Exp. Physiol. 99, 358-366. doi: 10.1113/expphysiol.2013.075812

Razon, S., Basevitch, I., Land, W., Thompson, B., and Tenenbaum, G. (2009). Perception of exertion and attention allocation as a function of visual and auditory conditions. Psychol. Sport Exerc. 10, 636-643. doi: 10.1016/j.psychsport.2009.03.007

Razon, S., Hutchinson, J. C., and Tenenbaum, G. (2012). "Effort Perception,” in Measurement in Sport and Exercise Psychology, eds G. Tenenbaum, R. Eklund, and A. Kamata (Champaign: Human Kinetics), 265-278.

Rejeski, W. (1985). Perceived exertion: an active or passive process? J. Sport Psychol. 7, 371-378.
Shephard, R. (2009). Comments on point: counterpoint: maximal oxygen uptake is/is not limited by a central nervous system governor. J. Appl. Physiol. 106, 343-346. doi: 10.1152/japplphysiol.zdg-8326.pcpcomm.2008

Tenenbaum, G., and Connolly, C. T. (2008). Attention allocation under varied workload and effort perception in rowers. Psychol. Sport Exerc. 9, 704-717. doi: 10.1016/j.psychsport.2007.09.002

Treisman, A. (1964). Selective attention in man. Br. Med. Bull. 20, 12-16.

Williamson, J., McColl, R., Mathews, D., Mitchell, J. H., Raven, P. B., and Morgan, W. P. (2002). Brain activation by central command during actual and imagined handgrip under hypnosis. J. Appl. Physiol. 92, 1317-1324. doi: 10.1152/japplphysiol.00939.2001

Williamson, J., McColl, R., Mathews, D., Mitchell, J., Raven, P., and Morgan, W. (2001). Hypnotic manipulation of effort sense during dynamic exercise: cardiovascular responses and brain activation. J. Appl. Physiol. 90, 1392-1399.

Wittekind, A. L., Micklewright, D., and Beneke, R. (2011). Teleoanticipation in all-out short-duration cycling. Br. J. Sports Med. 45, 114-119. doi: $10.1136 /$ bjsm. 2009.061580

Conflict of Interest Statement: The author declares that the research was conducted in the absence of any commercial or financial relationships that could be construed as a potential conflict of interest.

Copyright (c) 2015 Bigliassi. This is an open-access article distributed under the terms of the Creative Commons Attribution License (CC BY). The use, distribution or reproduction in other forums is permitted, provided the original author (s) or licensor are credited and that the original publication in this journal is cited, in accordance with accepted academic practice. No use, distribution or reproduction is permitted which does not comply with these terms. 